\title{
A Study on Media Regulation Experiences in Taiwan under Digital Governance
}

\author{
Yu-Chi Chen \\ Department of Public Administration and Policy, National Taipei University \\ johnny556173@gmail.com.
}

\begin{abstract}
The issue of regulation thinking versus improvement of industrial competitiveness has caused a lot of controversies among industries, government, and academia in Taiwan. The National Communications Commission has faced serious challenges in regulation thinking. On one hand, it has to worry about the input of a large amount of TV series from Mainland China. On the other hand, excessive protection policies for local TV industries may undermine self-competitiveness. Therefore, this study employed a literature review to describe the dilemma faced by media regulation experiences in Taiwan under digital governance.
\end{abstract}

Keywords: Digital governance; Media; Regulation; Soft power

\section{Introduction}

On November 9, 2005, the President of the R.O.C. officially promulgated the National Communications Commission Organization Act, which marked a new stage for Taiwan's governance and policy on communications. Furthermore, the widely criticized problems of communications by the Information Office, which acted as a government spokesman, seemed to be effectively resolved due to the establishment of NCC as an independent regulatory authority.

Due to technological advances, any information can be converted into digital signals that can then be passed on to customers via optical fiber, copper cable, or radio, which is the trend of digital convergence. Therefore, the reasons for regulation, apart from rare radio frequency, also include public control of radio channels, high penetration of media into households, the prevalence of communications, difficulties to control what is being viewed, the profound influence of the media, and the possibility of involuntary broadcasting and rapid reporting (Franklin, 2000). Under such influences and public opinions, digital governance is also an important topic for NCC to explore supervision and governance.

According to NCC's stated difficulties and problems in the development of the TV industry in Taiwan. Factors taken into consideration include the following: TV 
advertisement market is greatly reduced because of channel competition. The TV industry relies too much on rating indicators. The program costs are reduced because of reduced operating income. Management and regulatory policies need to consider the actual development of the TV industry and should have supporting measures.

The impact of mainland China's powerful film and television strength has contributed to drastic changes in Taiwan's local film and television industry. A wide range of mainland films and TV programs are played on major TV channels in Taiwan and appear to negatively impact the development of the local film and television industry. How should NCC supervise this to meet the public's interest? How can it balance and maintain the operation of a sound and free competitive market mechanism during the supervision?

\section{Overview of media regulation development in Taiwan}

Rosenbloom (2004:14), a well-known scholar in the field of public administration, defined public administration as "the process by which the legislative, executive and judicial departments of the government regulate or provide all or some services to the society." In other words, the function of the government is presented in its "services" or "regulation" to the public, and the fulfillment of the government's "services" must rely on the perfection and improvement of its "regulation" measures (Chang, 2007: 1).

Liberalism and neoliberalism have been widely discussed in the literature. Liberalism stresses the mechanism of the free market and advocates reducing government regulation of business practices and property rights. However, individualistic human nature contributes to the monopoly of contemporary capitalism, and so the free market has become a complete hypothesis, neoliberalism has revived, and government intervention has been employed to ensure the operation of the free market (Chu (trans) 2009: 3-14). "Market failure" is the most legitimate reason why the government regulates the private economy and social activities. However, welfare economists have long indicated that seldom does a perfect competition market exist, as most markets face "natural monopoly", "externality", "public goods", and "information asymmetry". Therefore, competitiveness has always been the focus of attention, and how NCC should appropriately supervise film and television has always been a very important topic.

Government regulation also means stipulation or supervision, is a concept of "government intervention", and indicates that the government naturally intervenes in its interactive industries by supervision, regulation, and stipulation through the media (Peng, 2012: 5). Hung (2006: 56) held that government authorities should not discard licensing as an important tool for structural regulation. Institutional design should attach importance to information disclosure and citizen participation in order to safeguard freedom of speech and public interest.

The development of Taiwan's media passed through several periods, including paper media, television media, cyber media, and digital convergence, ever since the ban 
on newspapers was lifted in $1988 .{ }^{1}$ With the rapid development of new media technologies, the media environment has undergone tremendous changes. A vast range of platforms has become increasingly fragmented, and the mastership of audiences is now increasingly strengthened (Lai, 2016: 147).

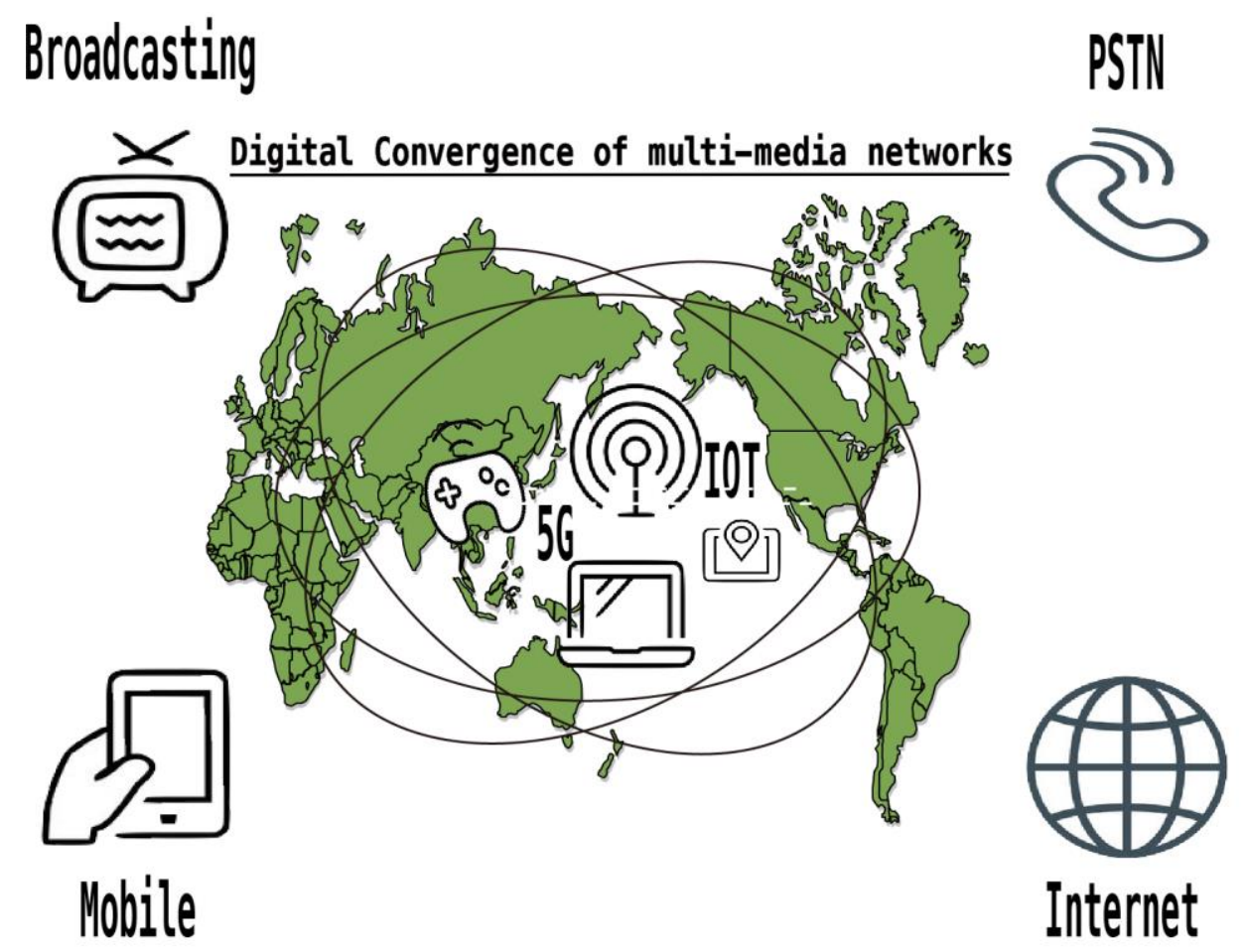

Figure 1. Relation Diagram of digital convergence.

Source: Compiled by this study.

As shown in Figure 1, In the era of "digital convergence", telecommunications and communications produce convergence effects. After the contents are digitalized, compression technology renders channels no longer "rare". The boundaries between different media are starting to blur and different forms of content ${ }^{2}$ produce convergence effects. Therefore, the vertical management model using "rarity" as the grounds for management or with the management goals of carriers follows the

\footnotetext{
${ }^{1}$ From the perspective of political operation, after different authorities, party-state politics had built a vertical regulation structure, and the government "even could directly operate the radio and television media through the party, government and military". Under the unity of operation and management, the state could freely manipulate everything the media says and does (Hung, 2006: 56).

2 The popularization of the Internet and myriad mobile devices was the best niche for the development of the OTT industry. According to a survey conducted by the Institute for Information Industry, $71 \%$ of the public watched films through mobile phones in the second quarter of last year, suggesting that viewing habits have begun to change (Chu, 2017a).
} 
principles of fairness, efficiency, convenience, harmony, and technology neutrality, but immediately faces the dilemma of difficulty in implementation.

\section{Competition and cooperation of cross-strait film and television power and soft power}

One of the examples of developing soft power $^{3}$ in mainland China is the production of TV dramas. We can get some clues from the development of cross-strait TV dramas whereby competition and cooperation in Taiwan can be divided into "infancy" (19581986), "boom" (1987-1999), "recession" (2000-2007), and "dawn" (2008-present). During "infancy", the Kuomintang and the Communist Party of China were sworn enemies in the cold war, and public media was reduced to a political tool for both parties to control ideology. During the "boom", the political tension between Taiwan and the mainland was reduced by the late 1980s. Their economies both opened up, and they started cultural and economic exchanges, contributing to a peak of cross-strait film and television exchange in the 1990s. During the "recession", in 2000 the State Administration of Press, Publication, Radio, Film and Television of the People's Republic of China (hereinafter referred to as "SARFT") introduced a policy of protective umbrella in order to "foster the prosperity of domestic TV dramas and further strengthen the macro-regulation of importing and co-producing TV dramas", which seriously frustrated Taiwanese television producers. SARFT promulgated the Notice Concerning Further Strengthening Television Drama Import, Co-Production and Broadcast Management", which strictly stipulated that "Of those, all television stations, cable radio and television stations, except for foreign dramas that SARFT has approved for broadcast, foreign dramas may not be scheduled for broadcast between 19:00 and 21:30". During the "dawn", Taiwan and the mainland both pursued a loose policy in which both approved that co-production dramas should be regarded as domestic dramas respectively; it was generally believed that this measure facilitated the circulation of co-production dramas in the cross-strait market (Wu and Chiang 2010: 5-13).

Television dramas and the media in mainland China are presently witnessing rapid development, and with impetus of its soft power, miscellaneous films, TV series, and variety shows are being exported to different countries. In order to effectively fuel the healthy development of the TV drama industry and enhance the quality of TV dramas (good dramas), SARFT now places great emphasis on enforcing the policy that "the same TV drama can be broadcast on only two television stations' satellite channel" and that "only two episodes of the same TV drama can be broadcast each night". ${ }^{4}$ This policy aims to de-stock TV dramas so that more TV dramas can be broadcast.

With respect to the total output of TV dramas approved for distribution from

\footnotetext{
${ }^{3}$ Hard power is a push, whereas soft power is a pull. In terms of a complete definition, "soft power is the ability to achieve the desired results by setting agenda, persuasion, raising positive attractiveness and other similar means" (Nye, 2011: 20-21; Li (trans), 2011: 44).

4 "The same TV drama can be broadcast on only two television stations' satellite channel during the prime time each night" and "only two episodes of one TV drama can be broadcast on satellite channels during the prime time each night".
} 
2004 to $2015,{ }^{5}$ that in 2012 was the highest with a total number of 509, but that in 2015 was 395 and that in 2016 was the lowest with a total number of $330 .^{6}$ These figures imply that the TV drama market in the mainland has always faced oversupply and has improved by emphasizing quality over quantity in 2013.

In terms of the total TV dramas in mainland China in $2016,{ }^{7}$ the $330 \mathrm{TV}$ series consisted of a total of 14,768 episodes, 119,895 minutes of TV animated films, 772 films, and 172 popular science films, documentaries, animated cartoons, and special films, which were all produced and approved for distribution. In contrast, the TV market in Taiwan is small and over-competitive and has gradually slumped due to limited production funds, which all halted the production and development of high-cost TV dramas (Wu and Chiang, 2010: 19).

Lai (2017b: 1) maintained that the power of Chinese film and television has risen, but it does not represent soft power. The power of film and television could be reflected by output value only. Nonetheless, the focus of soft power of film and television should be on shaping the positive image of a country, transmitting concepts to other countries, and hence affecting the trend of the world media and contributing to the revival of national confidence and recognition of the international community. As a result, the inadequacies of the film and television industry in mainland China are that its film and television power mainly hinges on its huge domestic market and not through any market for overseas audiences.

\section{Debate over regulation and open competition of Taiwan's film and television industry}

At the "Spring Festival Banquet for the TV Drama Industry" on February 7, 2017, President Tsai Ing-wen noted that "Our production is under-funded and the competitiveness of Taiwan TV programs is gradually falling compared with mainland China, Japan, and South Korea. Taiwan audiences are watching plenty of European, Japanese, and Korean TV dramas via the Internet."

It is a vicious circle that our outstanding technicians and performers, one after another, get into the film and television market in mainland China, which consequently impairs the production capacity of local film and television. As a result, President Tsai Ing-wen further stated that "The importance of the TV drama industry lies in how to present lifestyles, values and culture of the Taiwanese. It is hoped that outstanding local film and television contents and professionals and resources of related administrative

\footnotetext{
5 2016, "Good Dramas Are of Overriding Importance -- An Analysis of Quality Drama Resources of the TV Market in 2015", CSM Media Research: http://www.csm.com.cn/data/editor/pdf/5784a7c597285.pdf, Retrieved on December 25, 2016.

6 2017, "2016 Industry Survey Report on Locally Produced TV Dramas", National Bureau of Statistics of the People's Republic of China: http://www.stats.gov.cn/tjsj/tjgb/ndtjgb/, Retrieved on December 23, 2016.

7 2017, "Statistical Communiqué on National Economic and Social Development", Chinese Social Science Network: http://www.stats.gov.cn/tjsj/zxfb/201702/t20170228_1467424.html, Retrieved on December 27, 2017.
} 
organs, public broadcasting groups, foreign embassies, and foreign trade organizations can be brought together in order to build a national drama team that heads for every corner of the world." 8

NCC Chairperson Ting-I Chan has pushed for international cooperation and strengthened Taiwan's film and television industry. Confronted with the changes in the communications environment, online audio and video services are now the norm. Canada has long been invaded by the dominant culture of the United States, and so it protected its own film and television industry through a variety of measures. The Canadian government adjusted the policy on the film and television industry and resorted to active promotion based on the existing protection policy so that domestic film and television products could be competitive in the international market (NCC, 2017c).

The rise of streaming services has been at the forefront of the new digital landscape, which provides consumers with more options than ever before when it comes to viewing content. For years, Taiwan's cable TV has claimed the majority of TV viewership. According to Appendix 1. the penetration of cable TV is around $60 \%$ and stood at $60.77 \%$ at the end of second quarter 2017.

The reasons for the high penetration of cable TV are that

(a) The tariff for cable TV is about 16 to 20 USD per month, which is affordable for most households.

(b) Many of the cable TV operators have completed digitization that enables them to provide high-definition channels, as well as interactive services such as video on demand and multiscreen services.

NCC has so far issued more than 280 television licenses, but not every channel can be slotted on the platform for the cable television system. If the channels cannot be slotted on the platform, then they will never be watched. Put simply, just as a car can be parked if sold to someone who owns a parking lot, cable operators are parking lots and there are 299 cars now, but only 100 parking spaces are available. Therefore, competition is very intense. Industry insiders remark that "having a platform is always a winner". Moreover, some channel operators and MSOs (Multi-System Operators) ${ }^{9}$ have adopted an advertising profit-sharing mechanism in order to maintain the channels that they have been slotted.

\footnotetext{
8 2017, "The President Attends the Spring Festival Banquet for the TV Drama Industry", President of the Republic of China: http://www.president.gov.tw/Default.aspx?tabid=131\&itemid=38781\&rmid=514, Retrieved on February 9, 2017.

9 According to the statistics of NCC, there is a total of 5 MSOs in Taiwan, including Kbro, CNS, TBC, TFN, and TOP. The upstream of cable TV is channel content operators that bring channel content to MSOs. There are many independent system platforms under MSOs that deliver content to end consumers, while channel agents play an intermediary role between system operators and content operators.
} 


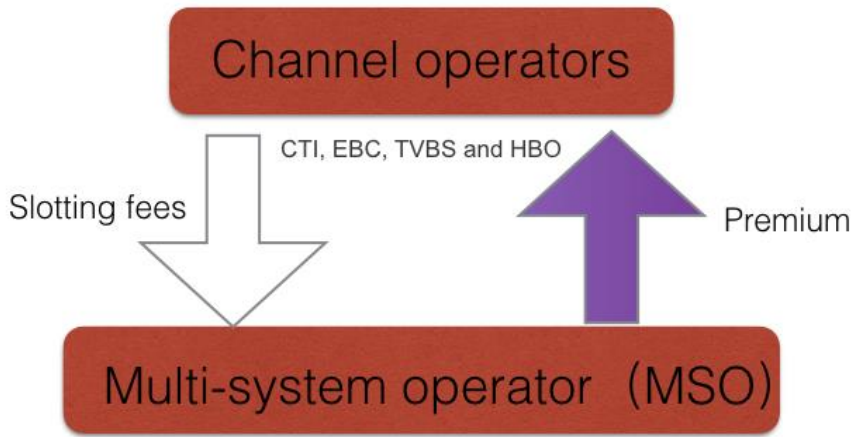

kbro (Fubon Group), CNS (MBK Partners, L.P.), TFN (Fubon Group), TBC (Macquarie Media), and Taiwan Optical Platform (TOP)

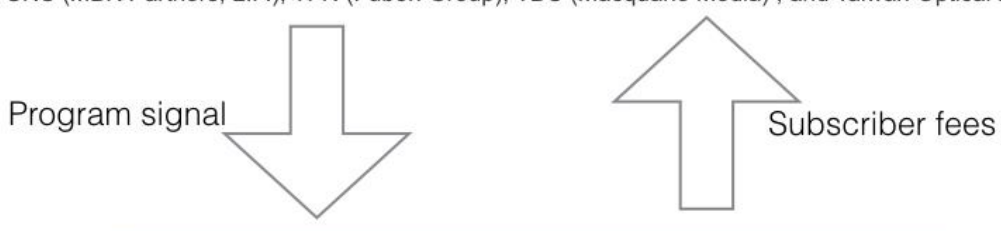

\section{Target audience}

Figure 2. Relation Diagram of Taiwan Cable TV Market.

Source: Compiled by this study.

Ya-chi Chiang (Yu-chi Chen, interview date: December 12, 2015) indicated that channels are short of money and that operators said that more money is needed to produce good channel content. As shown in Figure 2, in Taiwan's cable TV market, MSOs also act as channel agents and achieve vertical integration, and so they grasp the access and hence control whether to slot a channel or not. As a result, system operators prefer having their channels slotted, thus denying the opportunity of new channels with quality content to compete with them. NCC's regulatory dilemma is that this is a political issue rather than an industrial one. After more than one decade, no one in power has dared to make any changes.

\section{Conclusion}

Faced with intense competition in the film and television industry from mainland China, NCC is the organization in charge of supervising communications media in Taiwan. While stressing "freedom, competition, diversity, flexibility, and innovation", its responsibility is to execute comprehensive regulatory measures in order to maintain a sound and free competitive film and television market, so as to attract more foreign investment and to revitalize the overall market.

Lai (2017b: 1) believed that it is necessary to go global and not to stand still. The existing production model of Taiwan's TV dramas should shift from traditionally 
relying on advertising income from TV stations to attracting subscription income from target audiences. Professionals in big data analysis and segment marketing should also be nurtured for precise segment marketing.

Wei (2016) indicated that NCC can use the licensing procedure to set up a plural media environment and to require applicant obligations in supporting domestic media production. Secondly, NCC can plan to diversify media structures and options and to take transparent and democratic content regulation measures to promoting cultural diversity.

In the digital age, it is must to build strong trust relationship in a sustainable advertising field. In a web-built world, only the building of trust can keep the digital world up and running. "From regulation to deregulation " in response to the dynamic market, establishing criteria for regulatory intervention in dynamic markets and predicting the role of data is the goal in new markets. It is must to coordinate with interested parties.

The Institution of Watch Internet Network, also called "iWIN" is an example of successful "co-regulation" in Taiwan. The idea is to protect children from inappropriate online contents and create a healthy Internet environment for future generation. If anyone finds offensive posted online, they can immediately report it to IWIN. Then, the relevant authorities will take actions if the case is against the law; if the case is about improper contents, IWIN will cooperate with the platform providers a so-called "Notice and Takedown" procedure. It has already been shown an efficient way for internet governance in the digital world.

Based on the development of digital convergence, new types of film and television services such as digital TV and MOD are now emerging in Taiwan's film and television industry, but such services are still in their infancy. The film and television industry market should have more room for development and should be under "ex-ante regulation" by radio and television laws and regulations before they have a greater competitive edge. After the film and television industry market becomes more competitive, "post-hoc regulation" under the Fair Trade Act should be implemented to defend the competition mechanism of the film and television industry market. Finally, video websites should be actively encouraged to invest in producing high-quality video content to enhance the soft power of Taiwan's film and television industry.

\section{References}

Chen, Zhao ping. (2017).Traditional communications, radio and television media is eel, innovation and development rely on OTT this catfish. The Storm Media. Retrieved from http://www.storm.mg/article/138708

Franklin, M. A., Anderson, D. A., \& Cate, F. H. (2000). Mass Media Law: Cases and Materials (6th ed.). Eagan, MN: West Group.

Hau, Ming Wei (trans). (2012). The Rise and Fall of Neo-Liberalism. Beijing: Social 
Sciences Academic Press, trans from Theotonio dos Santos. Augey decadencia del neoliberalismo. C.A: Monte avila editors latinoamericana. 2006.

Hung, C. (2006). State regulation and the freedom of speech: A review of the renewal of satellite TV license. Journal of radio \& Television Studies, 26, 51-75.

Jang, Chyi Lu. (2006). Regulation: Theoretical and Empirical Analysis. Taipei: SCBOOKS.

Ju, Tseng Men (trans). (2009). Liberalism. Beijing : The Commercial Press, trans from Hobhouse, L. T. Liberalism. London, New York: Oxford university press. 1911.

Ju, Tze Wei. (2017a). OTT carve market cable operator: Unequal war. Central News Agency. Retrieved from http://www.cna.com.tw/news/afe/201712020034-1.aspx.

Ju, Tze Wei. (2017b). Make up for abandon channel agent losses. Central News Agency. Retrieved from http://www.cna.com.tw/news/afe/201712020035-1.aspx.

Kuo, Wu Yi \& Yi Hui Jiang. (2010). An exploration on the development and dilemma of co-production trendy drama. Tamkang Journal of Humanities and Social Sciences, 44, 1-26.

Lai, Hsiang Wai. (2014). Media confluence after the supervision of the problem. China Times. $\quad$ Retrieved from http://www.chinatimes.com/newspapers/20140725003225-260110

Lai, Hsiang Wai. (2016). Big Data and Ratings. Liu, Y.L. eds., Big Data and Future Communication. Taipei: Wunan Wunan Book. Co., Ltd.

Lai, Hsiang Wai. (2017a). Mainland China film still lacks soft power. China Times 2017/11/29, A15.

Lai, Hsiang Wai. (2017b). Reflections on the rise of mainland China 's film and television industry. Talk at the Taipei Forum. Retrieved from http://140.119.184.164/view/419.php.

Li, Jing Yi (trans). (2011). The Future of Power. Taipei:Commonwealth Publishing, trans from Nye, J. S. Vining. The Future of Power. New York: Public Affairs. 2010.

Lin, Shang Tzuo. (2017). Will establish a channel elimination mechanism kay guarantee: Will continue to cooperate with Dongsen and Weilai. The Storm Media. Retrieved from http://www.storm.mg/article/364316.

Liu, Jia wei., Lai, Ching min \& Kuo, Cheng hao. (2014). An analysis of Taiwan's licensing policy change: Relationship between media and state. The Chinese Public Administration Review, 20(3), 1-26.

NCC. (2017a). Alignment digital convergence blueprint. National Communications Commission official website. Retrieved from https://www.ncc.gov.tw/chinese/Report520.aspx\#.

NCC. (2017b). Complete communication related regulation. National Communications Commission official website. Retrived from https://www.ncc.gov.tw/chinese/Report520.aspx\#.

NCC. (2017c). Press release. National Communications Commission official website. Retrived from https://www.ncc.gov.tw/chinese/print.aspx?table_name=news\&site_content_sn= $8 \& s n \_f=37546$. 
Nye, J. S. (2011). The Future of Power. NY: Public Affairs.

Rosenbloom, D. H. \& R. S. Kravchuk. (2004). Public Administration: Understanding Management, Politics and Law in the Public Sector (6th ed.). NY: McGraw-Hill Publishing.

The Foundation for Excellent Journalism Award. (2008). Degradation of Key Forces Looking Back on the Ban for 20 Years. New Taipei City: Chuliu Publisher.

Wei Ti. (2006). Beyond supervision: Exploring the role of national communications commission in supporting media industries and developing media cultures. Journal of radio \& Television Studies, 26, 29-49.

Yun, Peng. (2012). NCC and Media Policy - Public Interest, Regulating Philosophy and Practice. New Taipei city: Storm Forum Company. 